\title{
B-cell populations discriminate between pediatric- and adult-onset multiple sclerosis
}

\section{OPEN}

Alexander Schwarz, MD

Bettina Balint, MD

Mirjam Korporal-

Kuhnke, MD

Sven Jarius, MD

Kathrin von Engelhardt, MD

Alexandra Fürwentsches, MD

Cornelia Bussmann, MD

Friedrich Ebinger, MD

Brigitte Wildemann, MD*

Jürgen Haas, $\mathrm{PhD}^{*}$

Correspondence to

Dr. Wildemann:

brigitte.wildemann@med.

uni-heidelberg.de
Supplemental data at Neurology.org/nn

\section{ABSTRACT}

Objective: To comparatively assess the B-cell composition in blood and CSF of patients with pediatric-onset multiple sclerosis (pedMS) and adult-onset multiple sclerosis (adMS).

Methods: In this cross-sectional study, we obtained blood and CSF samples from 25 patients with pedMS (8-18 years) and 40 patients with adMS (23-65 years) and blood specimens from 66 controls (1-55 years). By using multicolor flow cytometry, we identified naive, transitional, isotype class-switched memory, nonswitched memory, and double-negative memory B-cell subsets as well as plasmablasts (PB) and terminally differentiated plasma cells (PC). Flow cytometric data were compared to concentrations of B-cell-specific cytokines in serum and CSF as determined by ELISA.

Results: Frequencies of circulating naive B-cells decreased with higher age in controls but not in patients with multiple sclerosis (MS). B-cell patterns in CSF differed between pedMS and adMS with an acute relapse: in pedMS-derived CSF samples, high frequencies of nonswitched memory $B$ cells and PB were present, whereas class-switched memory B cells and PC dominated in the CSF of patients with adMS. In pedMS, PB were also elevated in the periphery. Accumulation of PB in the CSF correlated with high intrathecal CXCL-13 levels and augmented intrathecal synthesis of immunoglobulin $\mathrm{G}$ and immunoglobulin $\mathrm{M}$.

Conclusions: We demonstrate distinct changes in intrathecal B-cell homeostasis in patients with pedMS during active disease, which differ from those in adults by an expansion of plasmablasts in blood and CSF and similarly occur in prototypic autoantibody-driven autoimmune disorders. This emphasizes the particular importance of activated B-lymphocyte subsets for disease progression in the earliest clinical stages of MS. Neurol Neuroimmunol Neuroinflamm 2017;4:e309; doi: 10.1212/ NXI.0000000000000309

\section{GLOSSARY}

adMS = adult-onset multiple sclerosis; ASC = antibody-secreting cells; CIS = clinically isolated syndrome; CSM = classswitched memory; FITC = fluorescein isothiocyanate; IFN = interferon; IgG = immunoglobulin G; IgM = immunoglobulin M; IL = interleukin; $\mathbf{M S}=$ multiple sclerosis; $\mathbf{N M O}=$ neuromyelitis optica; $\mathbf{O N}=$ optic neuritis; PBMC = peripheral blood mononuclear cells; pedMS = pediatric-onset multiple sclerosis; $\mathbf{S L E}$ = systemic lupus erythematosus; USM = unswitched memory; VLA-4 = very late antigen-4.

Multiple sclerosis (MS) is an inflammatory disease of the CNS that usually becomes manifest between the ages of 20 and 40 years. Only about 3\%-4\% of patients experience their first symptoms prior to age 18 years. ${ }^{1,2}$ In the last decade, pharmacologic options to treat patients with adult-onset MS (adMS) have expanded remarkably, which raises our expectations of being able to transmit novel therapies to the pediatric-onset MS (pedMS) population. The feasibility of controlled clinical trials to generate data on the efficacy and safety of new drugs in pedMS is

\footnotetext{
*These authors share senior authorship.

From the Molecular Neuroimmunology Group (A.S., B.B., M.K.-K., S.J., B.W., J.H.), Department of Neurology, University Hospital of Heidelberg, Germany; Sobell Department of Motor Neuroscience and Movement Disorders (B.B.), UCL Institute of Neurology, London, UK; Department of Pediatric Neurology (K.v.E., A.F., C.B., F.E.), University Children's Hospital, Heidelberg; Department of Pediatrics (A.F.), University Medical Center Hamburg-Eppendorf, Hamburg; Child Neurology Practice (C.B.), ATOS Clinic Heidelberg; and Department of Child and Adolescent Medicine (F.E.), St. Vincenz-Krankenhaus, Paderborn, Germany.

Funding information and disclosures are provided at the end of the article. Go to Neurology.org/nn for full disclosure forms. The Article Processing Charge was paid by the Research Grant.

This is an open access article distributed under the terms of the Creative Commons Attribution-NonCommercial-NoDerivatives License 4.0 (CC BY-NC-ND), which permits downloading and sharing the work provided it is properly cited. The work cannot be changed in any way or used commercially without permission from the journal.
} 
limited due to the rarity of this entity. Diseasemodifying therapies are thus applied empirically in pedMS although the evidence of efficacy is insufficient. ${ }^{3}$ This seems reasonable as the pathophysiologic principles of adMS and pedMS are considered to be similar. However, substantial concerns remain since the developing immune system of younger people has specific properties and the clinical course of pedMS is characterized by higher inflammatory activity with more frequent relapses and a high risk of irreversible disability early in the course of disease., ${ }^{2,4}$ Therefore, it is important to identify immunologic similarities and differences between pedMS and adMS so as to better appraise treatment effects when novel drugs are applied in patients with pedMS. Here, we wanted to clarify whether the distinct homeostatic shifts within the B-cell compartment detectable in $\operatorname{adMS}^{7}$ can also be discerned in pedMS. This is of particular relevance because $\mathrm{B}$ cells are a target for immunotherapies in adMS, and B-cell-depleting drugs (rituximab, ocrelizumab, and ofatumumab) have recently shown impressive effects on the disease course and are likely to be approved for adMS in the near future. ${ }^{8-10}$

\begin{tabular}{|c|c|c|}
\hline \multirow[t]{2}{*}{ Demographic and clinical } & \multirow[b]{2}{*}{$\begin{array}{l}\text { Pediatric-onset } \\
\text { MS ( }=25)\end{array}$} & \multirow[b]{2}{*}{$\begin{array}{l}\text { Adult-onset } \\
\text { MS }(n=40)\end{array}$} \\
\hline & & \\
\hline Female, n (\%) & & $25(63)$ \\
\hline Median (range) age at sampling, $y$ & $16(8-18)$ & $33(23-65)$ \\
\hline Median (range) disease duration, y & $0.0(0-3)$ & $2.0(0-12)$ \\
\hline Median (range) EDSS at sampling & $1.0(0-3)$ & $1.5(0-4)$ \\
\hline In acute relapse, $n$ & 15 & 20 \\
\hline In clinical remission, $\mathrm{n}$ & 10 & 20 \\
\hline Blood samples, $n$ & 24 & 40 \\
\hline CSF samples, $n$ & 12 & 20 \\
\hline Mean CSF cell count, cells/ $\mu \mathrm{L}$ & 15.4 & 7.9 \\
\hline Mean (range) CSF cell count per sample & $20.8 \times 10^{3}(4.0-57.0)$ & $14.0 \times 10^{3}(3.0-40.5)$ \\
\hline Mean $Q_{A l b} \times 10^{-3}$ & 4.3 & 5.9 \\
\hline Median $\operatorname{Ig}_{\mathrm{IF}}, \%$ (range) & $1.5(0-94.7)$ & $0.0(0-0.27)$ \\
\hline Median $\operatorname{Ig} A_{\mathrm{IF}} \%$ (range) & $0.0(0-78.8)$ & $0.0(0-20.3)$ \\
\hline Median $\lg \mathrm{G}_{\mathrm{IF}}, \%$ (range) & $43.6(0-78)$ & $25.7(0-82.9)$ \\
\hline OCB, n (\%) & 25 (100) & 38 (95) \\
\hline
\end{tabular}

Abbreviations: EDSS = Expanded Disability Status Scale; IgA = immunoglobulin A; IgG = immunoglobulin $\mathrm{G}$; IgM = immunoglobulin $\mathrm{M}$; $\mathrm{MS}$ = multiple sclerosis; $\mathrm{OCB}=$ oligoclonal bands.
METHODS Study participants. In collaboration with the Department of Pediatric Neurology, University Children's Hospital, Heidelberg, we recruited 25 patients with pedMS according to the revised McDonald criteria ${ }^{11}$ and the consensus definitions proposed for pedMS and related disorders. ${ }^{1}$ All patients with pedMS had experienced their first symptoms at age $\leq 18$ years (median 16 years, range 8-18 years) and had not been treated with corticosteroids or disease-modifying drugs in the last month before study entry. The adMS cohort consisted of 40 untreated patients (median age 33 years, range 23-65 years). Blood-CSF barrier function was determined by nephelometrically assessing serum and CSF albumin concentrations and calculating the CSF to serum albumin ratio $\left(\mathrm{Q}_{\mathrm{alb}}=\right.$ albumin $\mathrm{CSF}[\mathrm{mg} / \mathrm{L}] /$ albumin serum $[\mathrm{mg} / \mathrm{L}] \times 10^{-3}$; normal $\left.=2-8\right) .{ }^{12}$ As controls, we included 39 children who were diagnosed with idiopathic adipositas or microsomia or who were scheduled for surgery for fronto-orbital advancement in craniosynostosis, as reported recently. ${ }^{13}$ According to age, we subdivided this group into children ( $\mathrm{n}=$ $22 ; 1-13$ years) and adolescents $(\mathrm{n}=17 ; 14-17$ years). To depict B-cell homeostasis over a broad age range, we also included 27 adult healthy volunteers (median age 37 years, range 25-55 years). Demographic and clinical data of all study participants are given in the table.

Standard protocol approvals, registrations, and patient consents. The study was approved by the ethics committee of the University Hospital Heidelberg. Written informed consent was obtained from all patients and parents.

Sampling. From all study participants, $10-50 \mathrm{~mL}$ peripheral blood and $10 \mathrm{~mL}$ serum were collected. Sera were immediately stored at $-70^{\circ} \mathrm{C}$. Peripheral blood mononuclear cells (PBMCs) were isolated from peripheral blood by Ficoll-gradient centrifugation (Biochrom, Berlin, Germany). Parallel CSF samples from 12 patients with pedMS and from 20 patients with adMS (0.5$3.0 \mathrm{~mL}$ ) were obtained by lumbar puncture, immediately placed on ice, and sedimented for 10 minutes at $300 \mathrm{~g}$ and $4^{\circ} \mathrm{C}$. Freshly isolated CSF cells were analyzed by flow cytometry. Supernatants were snap-frozen and stored at $-70^{\circ} \mathrm{C}$.

Multicolor flow cytometry. Flow cytometric B-cell analysis was performed as described before. ${ }^{7}$ Briefly, $1 \times 10^{6}$ PBMCs and, depending on cell count and volume of CSF samples, $3.0 \times 10^{3}$ to $5.7 \times 10^{4}\left(\right.$ mean $\left.1.65 \times 10^{4}\right)$ CSF cells were stained with monoclonal antibodies specific for human B-cell markers (CD20-PerCP, CD27-PE, immunoglobulin D-fluorescein isothiocyanate [FITC], CD38-APC, human leukocyte antigen-DRFITC, CD138-PE [BD Biosciences, Heidelberg, Germany]) and analyzed with a fluorescence-activated cell sorting Calibur cytometer and CellQuest software (BD Biosciences). Gating procedures are illustrated in figure e-1 at Neurology.org/nn.

ELISA. Cytokine levels of interleukin (IL) -6 and CXCL-13 in serum and CSF supernatants were determined by Human Quantikine HS ELISA Kits (R\&D Systems, Nordenstadt, Germany), according to the manufacturer's instructions. All samples were measured in duplicate.

Statistical analysis. Two-sided $t$ tests or 2-sided paired $t$ tests were used to compare normally distributed samples. MannWhitney $U$ tests or Wilcoxon tests were used to compare nonnormally distributed paired and unpaired samples. Q-Q plots were used to check for the normality assumption of a dataset. Correlations between 2 variables were calculated with Pearson correlation tests. $p<0.05$ Was considered statistically significant. $p$ Values were interpreted descriptive due to the exploratory character of the study, and thus, no adjustment for multiple testing was performed. 
RESULTS Frequencies of circulating naive and memory $B$ cells are age-dependent in control donors but not in patients with MS. First, we assessed physiologic B-cell homeostasis in blood specimens of 66 controls. We observed a clear age-related decline in naive $\mathrm{B}$ cells $(R=-0.724, p<0.00001)$ together with an increase in memory B cells (class-switched memory [CSM], unswitched memory [USM]) $(R=0.694$, $p<0.00001$ ) (figure 1). Highest concentrations of naive $\mathrm{B}$ cells and lowest frequencies of memory B cells were found in childhood (naive: 76.6\% $\pm 7.4 \%$; memory: $18.9 \% \pm 7.1 \%$ ) and in adolescence (naive: $73.8 \% \pm 8.3 \%$; memory: $21.5 \% \pm 7.8 \%$ ), while in adulthood a marked drop in the frequency of naive $\mathrm{B}$ cells along with a concomitant increase in percentages of memory B cells were detected (naive: $52.0 \% \pm 12.4 \%$; memory: $41.6 \% \pm 13.8 \%$ ).

When analyzing the composition of peripheral $\mathrm{B}$ cells in the MS cohort ( $\mathrm{n}=65$ ) we found no, or only moderate, age-dependent changes in both naive and memory B-cell subsets (naive: $R=-0.229, p=$ 0.07; memory: $R=0.162, p=0.034$ ) (figure 1 ). Correspondingly, the frequency of naive and memory B cells did not significantly differ between blood samples from patients with pedMS (naive: $68.3 \% \pm 11.4 \%$, memory: $38.1 \% \pm 20.9 \%$ ) and those from patients with adMS (naive: $63.6 \% \pm$ 14.3\%; memory: $42.8 \% \pm 20.1 \% ; p=0.45$ and 0.28 , respectively). Moreover, no age dependence was observed when the MS cohort was divided into subgroups of patients who were tested during acute relapse ( $\mathrm{n}=35$; naive $\mathrm{B}$ cells: $R=-0.211, p=$ 0.23 ; memory $\mathrm{B}$ cells: $R=0.357, p=0.038$ ) or while in clinical remission $(\mathrm{n}=30$; naive $\mathrm{B}$ cells: $R=-0.174, p=0.037$; memory $\mathrm{B}$ cells: $R=$ $0.145, p=0.045$ ) prior to regression analysis.

Changes in peripheral B-cell homeostasis are related to the stage of disease and differ in adMS and pedMS. An expansion of the relative frequency of naive $\mathrm{B}$ cells along with a concomitant reduction in CSM phenotypes in peripheral blood can typically be detected in patients with adMS with acute disease activity, as we have demonstrated previously. ${ }^{7}$ The comparative analysis of peripheral B-cell homeostasis in patients with adMS with clinically active $(\mathrm{n}=20)$ or clinically stable disease $(\mathrm{n}=20)$ performed in this study confirmed these data (naive B cells, relapse: $68.3 \% \pm 12.3 \%$ vs

Figure 1 Frequencies of naive and memory B cells (BC) are age-dependent in control donors but not in patients with multiple sclerosis (MS)
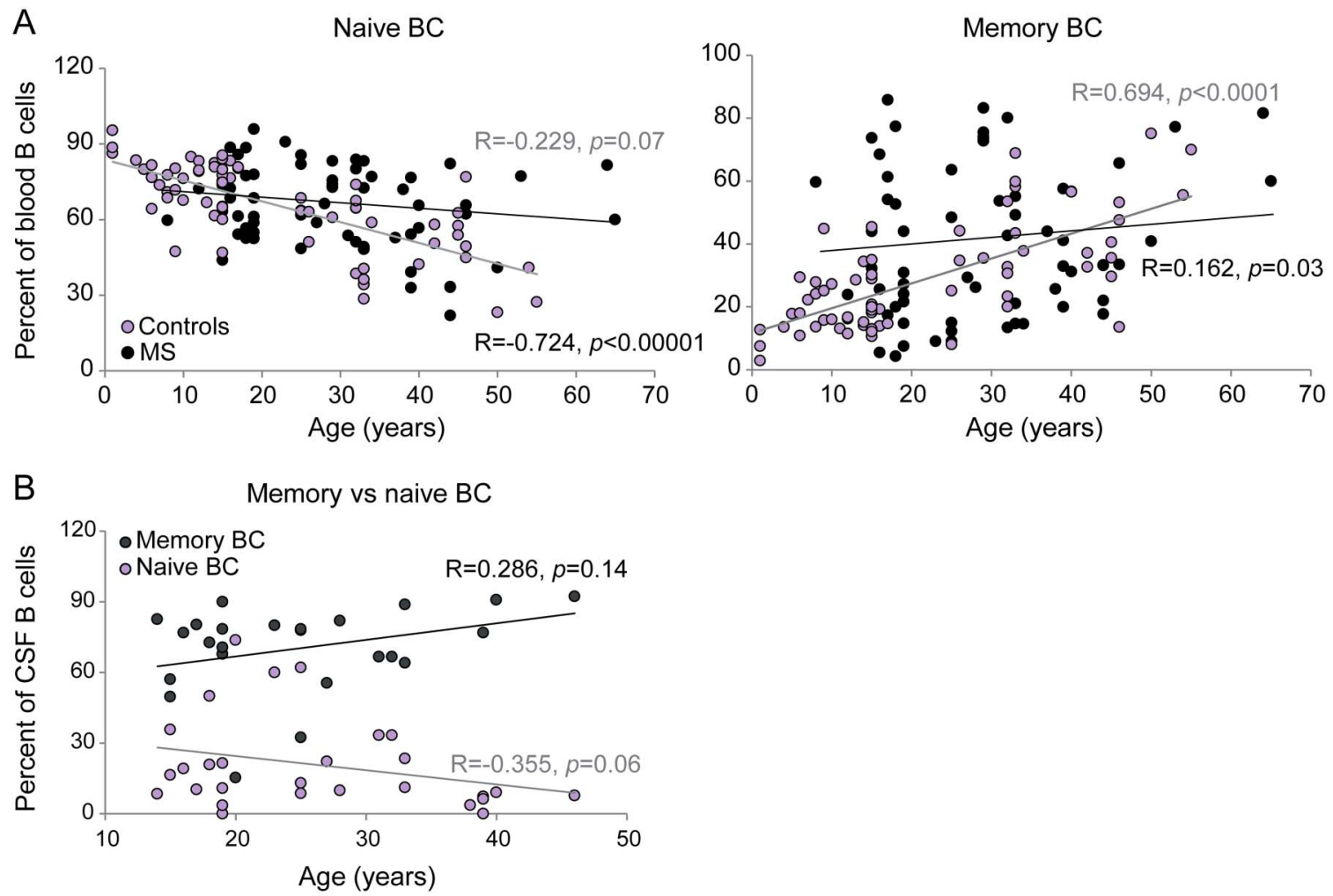

(A) Dot plots represent relative percentages of naive BC (left) and memory BC (right) in peripheral blood samples obtained from 66 control donors (gray circles) and 65 patients with MS (black circles), as determined by multicolor flow cytometry. Linear regression curves depict a decrease in naive BC with age in controls accompanied by an increase in memory $\mathrm{BC}$, whereas in the MS cohort no, or only moderate, age-dependent changes in both naive and memory BC were present. (B) Relative percentages of naive (white circles) and memory BC (filled circles) in CSF samples obtained from 28 patients with MS as determined by multicolor flow cytometry. Linear regression curves depict a moderate decrease in naive BC and increase in memory BC with age. Pearson correlation coefficients $(R)$ and statistical significances $(p)$ are indicated. 
remission: $57.5 \% \pm 15.9 \%, p=0.042$; CSM, relapse: $13.7 \% \pm 8.7 \%$ vs remission: $21.0 \% \pm 5.5 \%, p=$ 0.025 ) (figure $2 \mathrm{~A}$ ). Notably, similar alterations tended to be present in the pedMS cohort (naive B cells, relapse $[\mathrm{n}=15]: 73.3 \% \pm 11.4 \%$ vs remission $[\mathrm{n}=10]: 60.5 \% \pm 10.9 \%$, nonsignificant; CSM, relapse: $12.5 \% \pm 4.8 \%$ vs remission: $16.9 \% \pm$ $7.2 \%$, nonsignificant) (figure 2). However, unlike in adults, $\mathrm{PB}$ were expanded in the systemic circulation of patients with pedMS $(0.13 \% \pm 0.03 \%$ of PBMCs $)$ as a distinctive feature (figure $2 \mathrm{~B}$ ) and were 1.5-fold to 2fold higher than in the circulation of age-matched controls $(0.07 \% \pm 0.03 \%$ of PBMCs, $p=0.029)$.

Figure 2 Disease stage-dependent changes in blood-B-cell homeostasis are similar in adult-onset multiple sclerosis (adMS) and pediatric-onset multiple sclerosis (pedMS)

A

pedMS

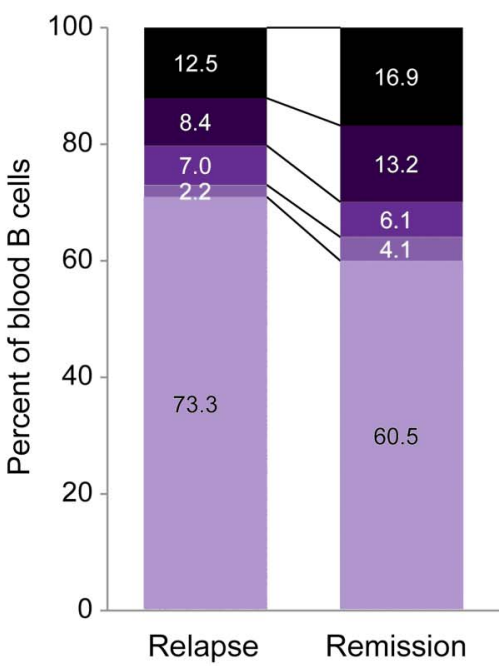

B
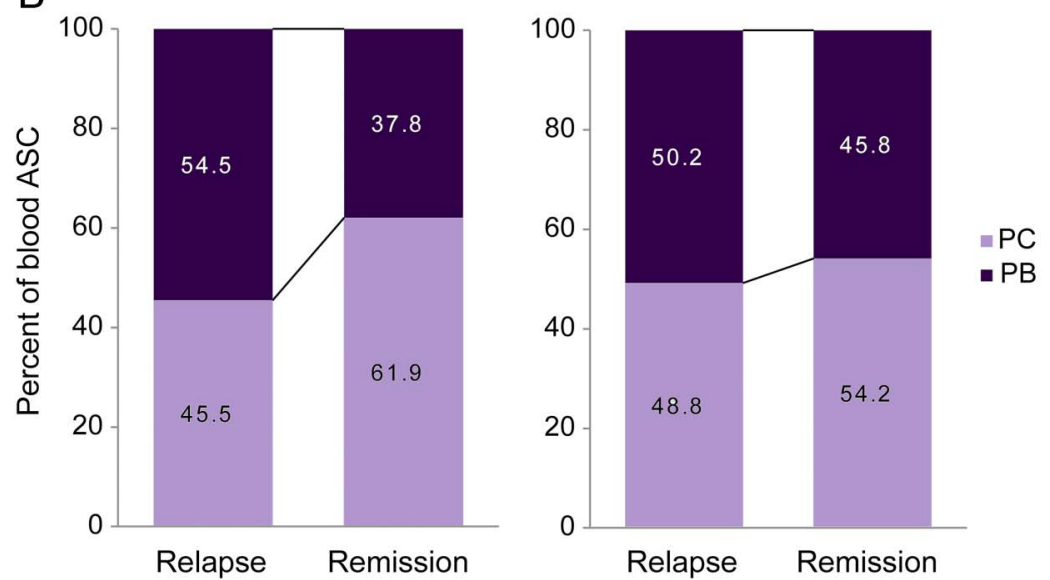

Stable bars represent percentages of (A) B-cell subsets and (B) antibody-secreting cells in the peripheral blood of 25 patients with pedMS (relapse: $n=15$; remission: $n=10$ ) and 40 patients with adMS (relapse: $n=20$; remission: $n=20$ ) as determined by multicolor flow cytometry. ASC = antibody-secreting cells; $\mathrm{CSM}$ = class-switched memory B cells; DNM = double-negative memory $\mathrm{B}$ cells; $\mathrm{PB}=$ plasmablasts; $\mathrm{PC}=$ plasma cells; $\mathrm{TN}=$ transitional $\mathrm{B}$ cells; USM = unswitched memory B cells.
The CSF of patients with pedMS exhibits distinct B-cell patterns. To depict the intrathecal B-cell compartment in pedMS, we assessed CSF specimens from 12 patients with pedMS and compared the data to those of 20 adult patients (all in relapse). In contrast to findings in blood, we found distinct differences between the 2 cohorts in CSF B-cell homeostasis. The divergences comprised a clear reduction in frequency of CSM-B cells and PC along with an increase in proportions of USM-B cells and of $\mathrm{PB}$ in CSF samples obtained from patients with pedMS (CSM: $36.6 \% \pm 18.2 \%$ of CSF B cells; USM: $29.4 \% \pm 10.7 \%$ of CSF B cells; PC: $42.9 \% \pm$ $15.9 \%$ of antibody-secreting cells [ASC]; PB: $56.2 \% \pm 16.9 \%$ of ASC) vs patients with adMS (CSM: $58.5 \% \pm 16.5 \%, p=0.013$; USM: $17.4 \% \pm$ $12.8 \%, p=0.037$; PC: $60.0 \% \pm 17.1 \%, p=0.044$; PB: $39.1 \% \pm 17.4 \%, p=0.048$ ) (figure 3).

When comparing absolute cell numbers in the CSF, we found higher cell counts for total B cells (328.8 cells/mL), USM (90.0 cells/mL), ASC (420.9 cells $/ \mathrm{mL})$, and PC (214.9 cells $/ \mathrm{mL})$ in pedMS than detected in adMS (total B cells: 168.7 cells $/ \mathrm{mL}, p=$ 0.078; USM: 27.2 cells $/ \mathrm{mL}, p=0.028$; ASC: 168.5 cells $/ \mathrm{mL}, p=0.015$; PB: 53.9 cells $/ \mathrm{mL}, p<0.001$ ).

High levels of CXCL-13 correlate with PB counts in the CSF of patients with pedMS. We used ELISA to determine concentrations of CXCL-13 and IL- 6 in CSF supernatants and parallel serum samples obtained from 12 patients with pedMS and 20 patients with adMS (all in acute relapse). On average, the concentrations of CXCL-13 in adMS-derived CSF were comparable to those reported earlier, ${ }^{7}$ yet showed a marked variability, with half of the samples tested having CXCL-13 concentrations near the detection limit of the ELISA assay used (2-4 pg/mL) and 4 specimens reaching levels $>100 \mathrm{pg} / \mathrm{mL}$. Although CXCL-13 levels in the CSF of patients with pedMS were universally higher than $10 \mathrm{pg} / \mathrm{mL}$, the difference between the 2 cohorts (pedMS: median $52.6 \mathrm{pg} / \mathrm{mL}$, range $11.5-203.2 \mathrm{pg} / \mathrm{mL}$; adMS: median $8.1 \mathrm{pg} / \mathrm{mL}$, range $3.0-224.7 \mathrm{pg} / \mathrm{mL}$ ) was not statistically significant $(p=0.142)$ (figure $4 \mathrm{~A}$ ). Notably, when comparing CXCL-13 data with numbers of B-cell subsets, the highest correlation was observed for total cell counts of PB in all CSF samples assessed $(R=0.712, p<0.001)$ (figure 4B). Interestingly, the 4 patients with adMS with high CXCL-13 levels in the CSF exhibited intrathecal pleocytosis (mean 16.5 CSF cells $/ \mu \mathrm{L}$ ), high PB counts (mean 132 cells $/ \mathrm{mL}$ ), and marked intrathecal immunoglobulin $\mathrm{G}$ ( $\mathrm{IgG}$ ) and immunoglobulin $\mathrm{M}$ (IgM) synthesis (medians, IgG 55.9\%, IgM 47.9\%), whereas the remaining 16 patients with adMS presented with lower CSF cell counts overall (mean 
Total B cells

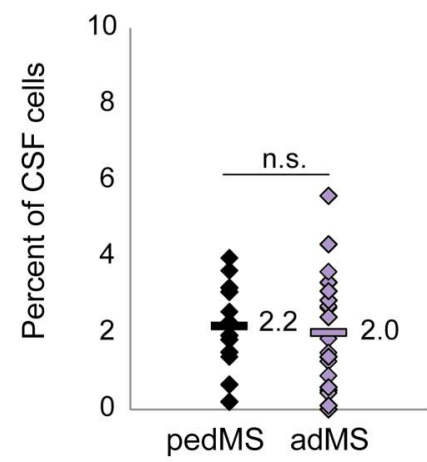

CSM B cells

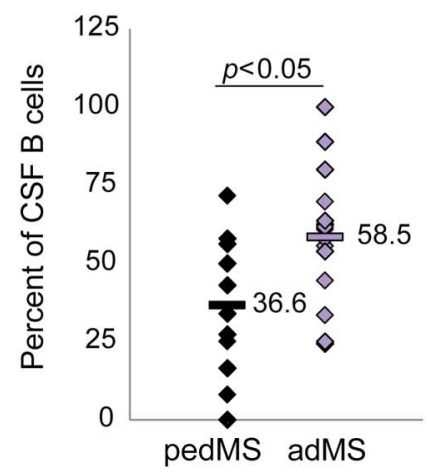

ASC

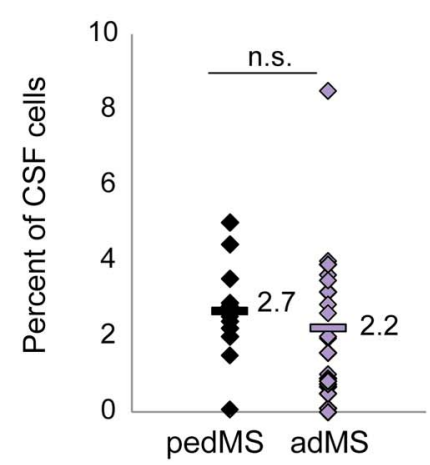

Naive B cells

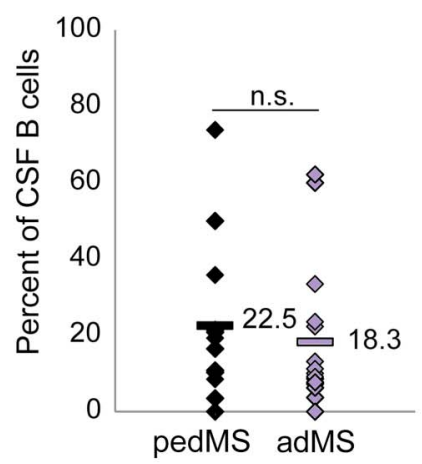

USM B cells

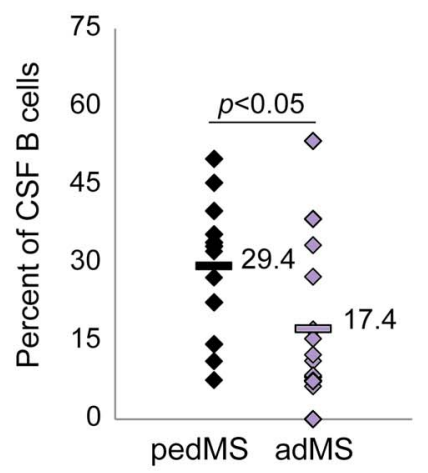

PC

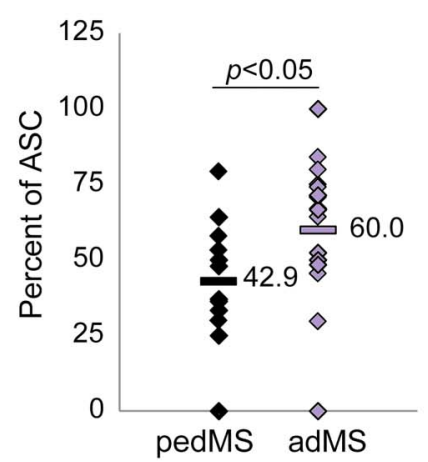

TN B cells

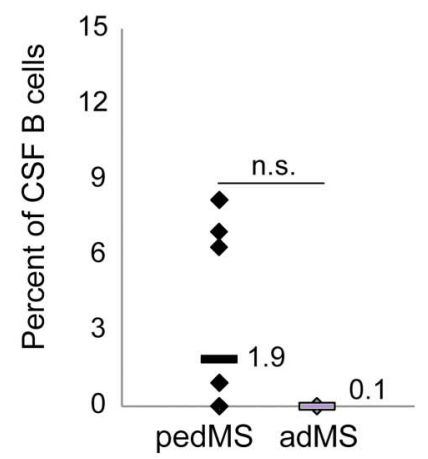

DNM B cells

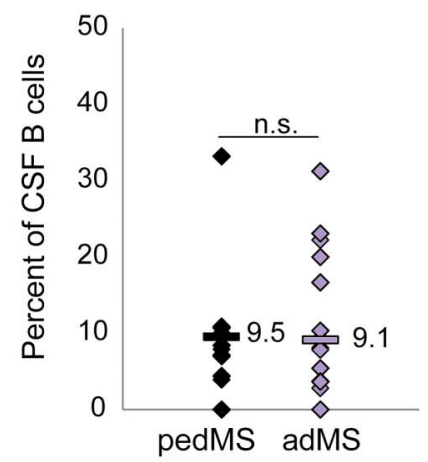

PB

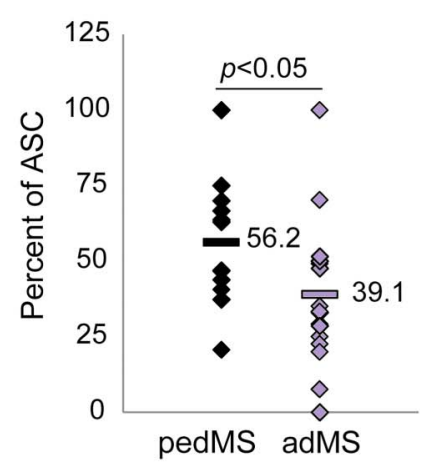

Scatterplots represent percentages of CSF B-cell subpopulations in patients with pedMS $(n=12)$ compared to patients with adult-onset multiple sclerosis (adMS) $(n=20)$ (all in acute relapse). The mean of each set of values is shown as a horizontal line. Statistical significances between different cohorts are indicated. ASC = antibody-secreting cells; CSM = class-switched memory B cells; DNM = double-negative memory B cells; n.s. = nonsignificant; $\mathrm{PB}$ = plasmablasts; $\mathrm{PC}=$ plasma cells; $\mathrm{TN}=$ transitional $\mathrm{B}$ cells; $\mathrm{USM}=$ unswitched memory B cells.

5.5 CSF cells/ $\mu \mathrm{L}, 54 \mathrm{~PB} / \mathrm{mL}$ ), and less pronounced intrathecal immunoglobulin synthesis (medians, IgG $15.0 \%$, IgM $0.0 \%$ ). In the parallel serum samples, CXCL-13 concentrations tended to be higher in pedMS (pedMS: median $66.1 \mathrm{pg} / \mathrm{mL}$, range $26.2-$ $349.5 \mathrm{pg} / \mathrm{mL}$; adMS: median $37.4 \mathrm{pg} / \mathrm{mL}$, range 24.0-301.5 pg/mL; nonsignificant with $p=$ 0.199 ) and did not correlate with intrathecal CXCL-13 levels or with the prevalence of B-cell subsets in either compartment. IL-6 levels were similarly low in CSF and serum of all patients tested, with no significant differences between pedMS and adMS cohorts.

DISCUSSION Current treatment of patients with pedMS occurs mostly under off-label conditions and, in terms of efficacy and safety, is based on therapeutic concepts developed and formally evaluated in adults. However, a potential concern of this approach is inherent in the different developmental stages of the pediatric and adult immune system, all the more so as modern disease-modifying drugs target distinct 
A. CXCL-13 in CSF

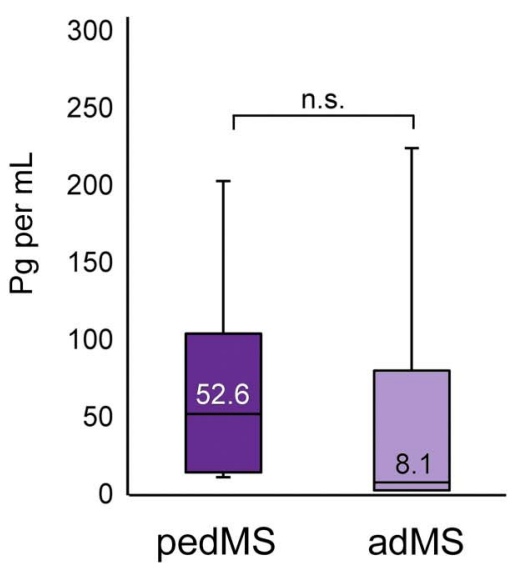

\section{B. CXCL-13 in CSF vs PB in CSF}

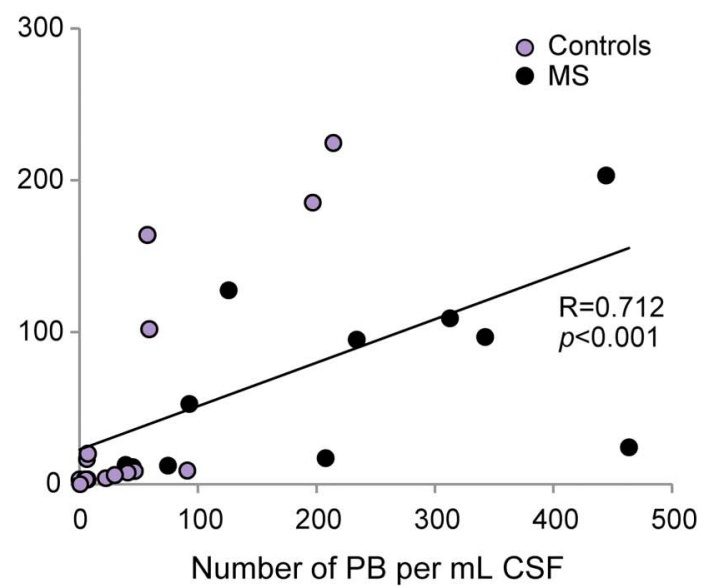

(A) CXCL-13 levels in CSF supernatants obtained from patients with pedMS $(n=12)$ compared to patients with adult-onset multiple sclerosis (adMS) ( $n=20$ ) (all in acute relapse) as determined by ELISA. Box plots show medians (line within the box), interquartile ranges (IQR, upper and lower limits of the box), and extreme values (lines extending from IQR). Statistical significance between study cohorts as determined by nonparametric, 2-tailed Wilcoxon-test test is indicated (n.s. = nonsignificant). (B) High correlation between CXCL-13 levels and numbers of plasmablasts in CSF samples of patients with multiple sclerosis (MS) (black circles = pedMS, gray circles = adMS). Each symbol represents one individual. Linear regression curve, Pearson correlation coefficient $(R)$, and corresponding $p$ value are shown. $\mathrm{PB}=$ plasmablasts.

populations of immune cells, which undergo dramatic changes in phenotype and frequency with aging. Such age-related differences also apply to B cells, an immune cell compartment that, according to current knowledge, is fundamentally involved in MS immunopathogenesis and counteracted by novel therapeutic strategies targeting the CD20 surface molecule, such as rituximab, ocrelizumab, and ofatumumab. ${ }^{14}$

Here, we first comprehensively assessed the phenotypes of peripheral B cells in a cohort of 66 control donors aged between 1 and 55 years to demonstrate that B-cell homeostasis undergoes marked changes as a function of age. While in peripheral blood of newborns more than $90 \%$ of B cells harbor a naive phenotype, the frequency of naive $\mathrm{B}$ cells decreases with age and, in line with the current literature, ${ }^{15}$ this natural decline is paralleled by a concomitant rise in proportions of antigen-experienced memory B cells. Notably, the age dependence in naive-to-memory ratios of peripheral B cells is nearly lost in individuals with MS aged between 12 and 55 years and this distinctive feature can already be discerned in the youngest patients. Accordingly, a considerable divergence in the naiveto-memory ratio was observed when comparing pediatric controls (14-17 years) with adult controls (25-55 years).

We next wondered whether MS-related alterations in peripheral B-cell homeostasis as previously described for adults ${ }^{7}$ are common or differ in patients with pedMS. Indeed, the abnormal B-cell pattern detectable in patients with pedMS during acute relapses largely matched those in adults, with an expanded circulating $\mathrm{CD} 27-\mathrm{IgD}+$ naive subset and a concomitantly contracted CD27+ memory B-cell pool, indicating compartmentalized shifts in B-cell subsets driven by acute MS disease activity. This finding implies that disease-specific variations in peripheral B-cell phenotypes take place independently of age and obviously resemble the marked and age-inappropriately altered naive-to-memory cell ratios affecting conventional and regulatory $\mathrm{T}$ cells as reported earlier. ${ }^{13}$ Interestingly, in contrast to adMS, PB-i.e., cells that are barely detectable in the periphery under normal conditions-turned out to be expanded overall in the pedMS cohort assessed here. Notably, heightened frequencies of circulating $\mathrm{PB}$ can also be detected in some prototypic, autoantibody-driven autoimmune disorders such as systemic lupus erythematosus (SLE) or neuromyelitis optica (NMO) ${ }^{16,17}$ and are considered to be a biomarker for disease activity. ${ }^{17}$

In our previous study, we found that relapseassociated shifts in peripheral B-cell profiles are closely related to crossover changes in the CSF that include intrathecal accumulation of CSM-B cells and ASC, in particular of mature PC. ${ }^{7}$ Here, multicolor flow cytometry assessment of CSF samples collected from 12 patients with pedMS and from 20 patients with adMS during active disease revealed similar intrathecal 
frequencies of total B cells and ASC, constituting approximately $2 \%$ and $3 \%$ of CSF cells, respectively. Likewise, antigen-experienced CD27+ memory B cells dominated in both cohorts, in contrast to the systemic circulation, where naive subtypes preponderated. Even so, the compartmentalized redistribution of B-cell phenotypes detectable in patients of all age groups markedly diverged in pedMS vs adMS. Pediatric patients not only displayed significantly higher CSF cell counts and increased intrathecal numbers of Blineage cells overall, but also a marked variation in the composition of the memory cell and ASC cell fractions. Unlike in the CSF of adults, where the vast majority of memory cells consisted of CSM-B cells in this and in a previous study, ${ }^{7}$ total B cells were clearly enriched in USM phenotypes in the CSF of patients with pedMS. This disparity in relative proportions of isotype class-switched and nonswitched memory subsets was paralleled by reciprocally distributed ASC subtypes between study cohorts. In pedMS, intrathecal ASC comprised predominantly $\mathrm{PB}$ with a $\mathrm{PB}: \mathrm{PC}$ ratio of 3:2 - a feature correlating with more pronounced intrathecal IgG and IgM synthesis-whereas their counterparts in adMS contained higher amounts of terminally differentiated $\mathrm{PC}$, resulting in a $\mathrm{PB}: \mathrm{PC}$ ratio of 2:3, as also described earlier. ${ }^{7}$ Notably, patients with pedMS exhibiting enhanced proportions of intrathecal $\mathrm{PB}$ correspondingly had a high frequency of $\mathrm{PB}$ in peripheral blood. A numerical increase in $\mathrm{PB}$ in the target organ or in the systemic circulation has been reported in several autoimmune diseases characterized by a strong humoral component in their pathology, such as NMO, ${ }^{16}$ Sjögren syndrome, ${ }^{18}$ pediatric ulcerative colitis, ${ }^{19} \mathrm{SLE},{ }^{17}$ and rheumatoid arthritis, ${ }^{20}$ thus supporting the perception that expanded $\mathrm{PB}$ might be involved in tissue damage associated with these disorders.

Evidence that PB also might contribute to the immunopathogenesis of early-stage MS comes from a recent study that demonstrated unique expansion of $\mathrm{PB}$ in the CSF of patients presenting with transverse myelitis as manifestation of a clinically isolated syndrome (CIS) suggestive of MS. ${ }^{21}$ Here, patients with CIS with transverse myelitis had a worse prognosis than patients presenting with optic neuritis (ON) when converted into definite MS. ${ }^{22-25}$ In that study, intrathecal accumulation of $\mathrm{PB}$ was exclusively seen in patients with CIS with transverse myelitis but not in those with $\mathrm{ON}$, and-akin to the patients with pedMS assessed here-was accompanied by expanded PB in the periphery. ${ }^{21}$

The accrual of $\mathrm{PB}$ in the systemic circulation might result from the activation of $\mathrm{B}$ cells in the periphery before they are recruited into the CNS to exert effector functions and to participate in the formation of ectopic germinal centers in the meninges. ${ }^{26,27}$ Unlike mature
PC, PB are motile cells ${ }^{28}$ and are able to traffic to the CSF through an integrin $\alpha 4 \beta 1$ (very late antigen-4 [VLA-4])-dependent mechanism as, similar to memory B cells, they express high levels of VLA-4. ${ }^{29,30}$ Accordingly, treatment with natalizumab, which inhibits the entry of immune cells into the CNS by blocking VLA-4, was more efficacious in patients with MS who had low intrathecal PB counts prior to initiation of therapy. ${ }^{31}$ In the present study, intrathecal expansion of $\mathrm{PB}$ in pedMS coincided with high CSF levels of CXCL-13, a chemokine promoting recruitment and maintenance of effector B cells in the CNS, which was shown to be elevated in the CSF of patients with MS during active and stable MS. ${ }^{7,32}$ In contrast, IL-6, a proinflammatory cytokine and important survival factor for $\mathrm{PB}$ that is considered to play a relevant role in $\mathrm{NMO}^{16}$ and in patients with MS who do not respond to interferon (IFN) $-\beta$ treatment, ${ }^{33}$ was not elevated in the CSF or serum of our study cohorts.

Despite the fact that, due to the exploratory character of our study, no corrections for multiple comparisons were performed and caution must be exercised when interpreting the significance level of our data, our observations clearly support the perception that the expansion of PB in the CSF and blood of patients with pedMS might be directly linked to MS disease progression. This is further underlined by results from earlier studies showing that intrathecal PB correlate with acute brain inflammation in MS as evidenced by $\mathrm{MRI}^{34}$ and with inflammatory CSF parameters such as leukocyte count, intrathecal synthesis of $\operatorname{IgM}$ and $\operatorname{IgG}$, and intrathecal production of matrix metalloproteinase-9 and CXCL-13..$^{34,35} \mathrm{With}$ respect to long-term outcome, children and adolescents with MS have higher relapse rates, ${ }^{4}$ usually reach milestones of disability about 10 years earlier, ${ }^{36}$ and have a higher MRI disease burden at presentation along with higher disease activity on follow-up scans than adults at the same disease stage. ${ }^{37}$ The more pronounced acute axonal damage in inflammatory demyelinating lesions of patients with pedMS vs patients with adMS reported recently ${ }^{38}$ also fits with the overall poor clinical prognosis of pediatric-onset MS. Hence, one might speculate that expanded $\mathrm{PB}$ are an important biomarker for early-stage MS and indicative of worse prognosis and rapid disease progression. The therapeutic relevance of this fact for pedMS is underlined by the PB dependency of natalizumab and IFN- $\beta$ treatment ${ }^{31,33}$ mentioned above as well as by the significant reduction in $\mathrm{PB}$ in response to rituximab therapy. ${ }^{39}$

Our results pinpoint pedMS-specific alterations of the B-cell compartment in the CNS and support the role of B cells and humoral immunity as an important component of MS pathology in young patients with early-stage MS. 


\section{AUTHOR CONTRIBUTIONS}

Study concept and design: Drs. Wildemann and Haas. Acquisition of data: Drs. Haas, Balint, Schwarz, and Korporal-Kuhnke. Analysis and interpretation of data: Drs. Schwarz, Wildemann, and Haas. Drafting of the manuscript: Drs. Haas and Schwarz. Critical revision of the manuscript for important intellectual content: Drs. Wildemann, Haas, Schwarz, and Jarius. Statistical analysis: Drs. Schwarz and Haas. Administrative, technical, and material support: Drs. Fürwentsches, Engelhardt, Bussmann, and Ebinger. Study supervision: Drs. Wildemann and Haas.

\section{ACKNOWLEDGMENT}

The authors thank the patients, control subjects, and their parents for participating in this study; and Brigitte Fritz and Silvia Zacharevics for technical assistance.

\section{STUDY FUNDING}

Supported by grants from the German Ministry for Education and Research (BMBF, "German Competence Network Multiple Sclerosis" [KKNMS], "Understand MS," and Research Consortium 3: "Prognostic and Treatment Markers") and Novartis.

\section{DISCLOSURE}

A. Schwarz received speaker honoraria from F. Hoffman-La Roche Ltd. and research support from Gemmeinnützige Hertiestiftung. B. Balint received travel funding and/or speaker honoraria from Movement Disorder Society and University of Leuven and research support from Gossweiler Foundation. M. Korporal-Kuhnke, S. Jarius, K. von Engelhardt, A. Fuerwentsches, and C. Bussmann report no disclosures. F. Ebinger served on the advisory board for Merck Serono and received speaker honoraria from Initiative Schmerzolos. B.T. Wildemann served on the scientific advisory board for Novartis, Merck Serono, and Genzyme, a Sanofi Company; received travel funding and/or speaker honoraria from Bayer Healthcare, Biogen, Merck Serono, Genzyme, a Sanofi Company, Novartis Pharmaceuticals, and Teva Pharma; and received research support from Biogen Idec, Merck Serono, Novartis Pharmaceuticals, Teva Pharma, the Dietmar Hopp Foundation, the Klaus Tschira Foundation, and the German Ministry of Education and Research (BMBF). J. Haas reports no disclosures. Go to Neurology.org/nn for full disclosure forms.

Received August 25, 2016. Accepted in final form October 31, 2016.

\section{REFERENCES}

1. Chitnis $\mathrm{T}$, Tenembaum S, Banwell B, et al. Consensus statement: evaluation of new and existing therapeutics for pediatric multiple sclerosis. Mult Scler 2012;18:116-127.

2. Boiko A, Vorobeychik G, Paty D, Devonshire V, Sadovnick D. Early onset multiple sclerosis: a longitudinal study. Neurology 2002;59:1006-1010.

3. Narula S, Hopkins SE, Banwell B. Treatment of pediatric multiple sclerosis. Curr Treat Options Neurol 2015;17:336.

4. Gorman MP, Healy BC, Polgar-Turcsanyi M, Chitnis T. Increased relapse rate in pediatric-onset compared with adult-onset multiple sclerosis. Arch Neurol 2009;66:54-59.

5. Banwell B, Ghezzi A, Bar-Or A, Mikaeloff Y, Tardieu M. Multiple sclerosis in children: clinical diagnosis, therapeutic strategies, and future directions. Lancet Neurol 2007;6: 887-902.

6. Renoux C, Vukusic S, Mikaeloff Y, et al. Natural history of multiple sclerosis with childhood onset. N Engl J Med 2007;365:2603-2613.

7. Haas J, Bekeredjian-Ding I, Milkova M, et al. B cells undergo unique compartmentalized redistribution in multiple sclerosis. J Autoimmun 2011;37:289-299.

8. Hauser SL, Comi GC, Hartung HP, et al. Efficacy and safety of ocrelizumab in relapsing multiple sclerosis: results of the interferon-beta-1a-controlled, double blind, phase III OPERA I and II studies. Mult Scler 2015;21(suppl):61-62.
9. Montalban X, Hemmer B, Rammohan K, et al. Efficacy and safety of ocrelizumab in primary progressive multiple sclerosis: results of the placebo-controlled, double-blind, phase III ORATORIO study. Mult Scler 2015;21(suppl):781-782.

10. Sorensen PS, Lisby S, Grove R, et al. Safety and efficacy of ofatumumab in relapsing-remitting multiple sclerosis: a phase 2 study. Neurology 2014;82:573-581.

11. Polman CH, Reingold SC, Banwell B, et al. Diagnostic criteria for multiple sclerosis: 2010 revisions to the McDonald criteria. Ann Neurol 2011;69:292-302.

12. Reiber H, Ungefehr S, Jacobi C. The intrathecal, polyspecific and oligoclonal immune response in multiple sclerosis. Mult Scler 1998;4:111-117.

13. Balint B, Haas J, Schwarz A, et al. T-cell homeostasis in pediatric multiple sclerosis: old cells in young patients. Neurology 2013;81:784-792.

14. Milo R. Therapeutic strategies targeting B-cells in multiple sclerosis. Autoimmun Rev 2016;15:714-718. Review.

15. Duchamp M, Sterlin D, Diabate A, et al. B-cell subpopulations in children: national reference values. Immun Inflamm Dis 2014;2:131-140.

16. Chihara N, Aranami T, Oki S, et al. Plasmablasts as migratory IgG-producing cells in the pathogenesis of neuromyelitis optica. PLoS One 2013;8:e83036.

17. Boekel ET, Prins M, Vrielink GJ, de Kieviet W, Siegert CE. Longitudinal studies of the association between peripheral CD27++ plasma cells and systemic lupus erythematosus disease activity: preliminary results. Ann Rheum Dis 2011;70:1341-1342.

18. Hansen A, Odendahl M, Reiter $K$, et al. Diminished peripheral blood memory $\mathrm{B}$ cells and accumulation of memory B cells in the salivary glands of patients with Sjogren's syndrome. Arthritis Rheum 2002;46:2160-2171.

19. Tarlton NJ, Green CM, Lazarus NH, et al. Plasmablast frequency and trafficking receptor expression are altered in pediatric ulcerative colitis. Inflamm Bowel Dis 2012;18: 2381-2391.

20. Sellam J, Rouanet $\mathrm{S}$, Hendel-Chavez $\mathrm{H}$, et al. Blood memory $\mathrm{B}$ cells are disturbed and predict the response to rituximab in patients with rheumatoid arthritis. Arthritis Rheum 2011;63:3692-3701.

21. Ligocki AJ, Rounds WH, Cameron EM, et al. Expansion of CD27high plasmablasts in transverse myelitis patients that utilize VH4 and JH6 genes and undergo extensive somatic hypermutation. Genes Immun 2013;14:291-301.

22. Tintore M, Rovira A, Arrambide G, et al. Brainstem lesions in clinically isolated syndromes. Neurology 2010;75: 1933-1938.

23. Gajofatto A, Monaco S, Fiorini M, et al. Assessment of outcome predictors in first-episode acute myelitis: a retrospective study of 53 cases. Arch Neurol 2010;67:724-730.

24. Miller D, Barkhof F, Montalban X, Thompson A, Filippi M. Clinically isolated syndromes suggestive of multiple sclerosis, part I: natural history, pathogenesis, diagnosis, and prognosis. Lancet Neurol 2005;4:281-288.

25. Atkins EJ, Biousse V, Newman NJ. Optic neuritis. Semin Neurol 2007;27:211-220.

26. Corcione A, Aloisi F, Serafini B, et al. B-cell differentiation in the CNS of patients with multiple sclerosis. Autoimmun Rev 2005;4:549-554.

27. Serafini B, Rosicarelli B, Magliozzi R, Stigliano E, Aloisi F. Detection of ectopic B-cell follicles with germinal centers in the meninges of patients with secondary progressive multiple sclerosis. Brain Pathol 2004;14:164-174. 
28. Odendahl M, Mei H, Hoyer BF, et al. Generation of migratory antigen-specific plasma blasts and mobilization of resident plasma cells in a secondary immune response. Blood 2005; 105:1614-1621.

29. Planas R, Jelcic I, Schippling S, Martin R, Sospedra M. Natalizumab treatment perturbs memory- and marginal zone-like B-cell homing in secondary lymphoid organs in multiple sclerosis. Eur J Immunol 2011;42: 790-798.

30. Kleine TO, Benes L. Immune surveillance of the human central nervous system (CNS): different migration pathways of immune cells through the blood-brain barrier and blood-cerebrospinal fluid barrier in healthy persons. Cytometry A 2006;69: 147-151.

31. Villar LM, Garcia-Sanchez MI, Costa-Frossard L, et al. Immunological markers of optimal response to natalizumab in multiple sclerosis. Arch Neurol 2012;69 191-197.

32. Krumbholz M, Theil D, Cepok S, et al. Chemokines in multiple sclerosis: CXCL12 and CXCL13 up-regulation is differentially linked to CNS immune cell recruitment. Brain 2006;129:200-211.
33. Nakamura M, Araki M, Yamamura T. Plasmablast in the pathology of multiple sclerosis. Nihon Rinsho Meneki Gakkai Kaishi 2015;38:403-411.

34. Kuenz B, Lutterotti A, Ehling R, et al. Cerebrospinal fluid $\mathrm{B}$ cells correlate with early brain inflammation in multiple sclerosis. PLoS One 2008;3:e2559.

35. Tumani H, Hartung HP, Hemmer B, et al; BioMS Study Group. Cerebrospinal fluid biomarkers in multiple sclerosis. Neurobiol Dis 2009;35:117-127.

36. Simone IL, Carrara D, Tortorella C, et al. Course and prognosis in early-onset MS: comparison with adultonset forms. Neurology 2002;59:1922-1928.

37. Waubant E, Chabas D, Okuda DT, et al. Difference in disease burden and activity in pediatric patients on brain magnetic resonance imaging at time of multiple sclerosis onset vs adults. Arch Neurol 2009;66:967-971.

38. Pfeifenbring S, Bunyan RF, Metz I, et al. Extensive acute axonal damage in pediatric multiple sclerosis lesions. Ann Neurol 2015;77:655-667.

39. Hachiya Y, Uruha A, Kasai-Yoshida E, et al. Rituximab ameliorates anti-N-methyl-D-aspartate receptor encephalitis by removal of short-lived plasmablasts. J Neuroimmunol 2013;265:128-130. 


\section{Neurology \\ Neuroimmunology \& Neuroinflammation}

\section{B-cell populations discriminate between pediatric- and adult-onset multiple sclerosis}

Alexander Schwarz, Bettina Balint, Mirjam Korporal-Kuhnke, et al.

Neurol Neuroimmunol Neuroinflamm 2017;4;

DOI 10.1212/NXI.0000000000000309

This information is current as of December 15, 2016

\section{Updated Information \& Services}

Supplementary Material

References

Subspecialty Collections

Permissions \& Licensing

Reprints including high resolution figures, can be found at:

http://nn.neurology.org/content/4/1/e309.full.html

Supplementary material can be found at:

http://nn.neurology.org/content/suppl/2016/12/15/4.1.e309.DC1

This article cites 39 articles, 2 of which you can access for free at: http://nn.neurology.org/content/4/1/e309.full.html\#\#ref-list-1

This article, along with others on similar topics, appears in the following collection(s):

All Pediatric

http://nn.neurology.org//cgi/collection/all_pediatric

Cerebrospinal Fluid

http://nn.neurology.org//cgi/collection/cerebrospinal_fluid

Multiple sclerosis

http://nn.neurology.org//cgi/collection/multiple_sclerosis

Information about reproducing this article in parts (figures,tables) or in its entirety can be found online at:

http://nn.neurology.org/misc/about.xhtml\#permissions

Information about ordering reprints can be found online: http://nn.neurology.org/misc/addir.xhtml\#reprintsus

Neurol Neuroimmunol Neuroinflamm is an official journal of the American Academy of Neurology.

Published since April 2014, it is an open-access, online-only, continuous publication journal. Copyright

Copyright (C) 2016 The Author(s). Published by Wolters Kluwer Health, Inc. on behalf of the American

Academy of Neurology. All rights reserved. Online ISSN: 2332-7812.

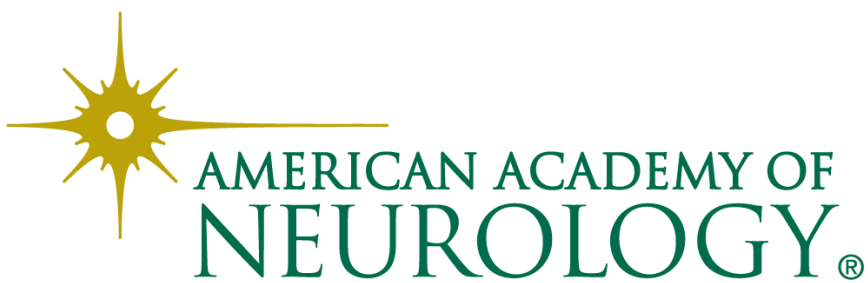

